\title{
Investigating different cultural factors on establishment of knowledge management in educational organization
}

\author{
Ali Makhsousi ${ }^{a^{*}}$, Jamshid Salehi Sadaghiani ${ }^{b^{*}}$ and Maghsoud Amiri ${ }^{\mathrm{c}}$
}

${ }^{a}$ M.A. Student, Department of public adminstration, School of Management, Tehran North Branch, Islamic Azad University (IAU), Tehran, Iran ${ }^{b}$ Prof.\& Faculty Member, Department of Management, School of Management \& Accounting, Allameh Tabatabaee University, Tehran, Iran ${ }^{c}$ Assist. Prof. \& Faculty Member, Department of Management, School of Management\& Accounting, Allameh Tabatabaee University, Tehran, Iran

\section{H R O N I C L E}

\section{Article history:}

Received October 25, 2012

Received in revised format

8 December 2012

Accepted 10 December 2012

Available online

December 112012

Keywords:

Knowledge management

Educational organizations

Regression analysis

Cultural factors

\section{Introduction}

Knowledge management is one of the most important components in improving the efficiency of organizations (Asgari, 2005). However, building a knowledge management framework within any organization may not be an easy task since there are some major barriers in reaching the objectives. Therefore, there have been many studies associated with finding major obstacles surrounding knowledge management implementation. Azad et al. (2012) investigated six factors associated with knowledge management including concept of knowledge, management, knowledge tools, knowledge measurement, change management, knowledge content. They used LISREL software package to determine the relationship between entrepreneurship and knowledge management components. Based on the results of this survey, knowledge content was number one priority followed by knowledge

Corresponding author. Tel: +989121992538

E-mail: makhsousi1979@yahoo.com (A. Makhsousi)

(c) 2013 Growing Science Ltd. All rights reserved. doi: 10.5267/j.msl.2012.12.012

\begin{abstract}
Knowledge management plays an essential role on developing efficient systems in educational systems. However, there are different factors influencing the success of knowledge management. In this paper, we present an empirical study to measure the impact of six cultural based factors including management support, organizational affiliation, employee participation in decision-making, staff welfare organization and establishment, adaptation of new policies and organizational and internal organizational climate on establishment of knowledge management. The proposed study of this paper is implemented in 114 selected educational organizations in city of Tehran, Iran. A questionnaire is designed in Likert scale, it is distributed among experts, and using regressions analysis and structural equation modeling, we have analyzed the data. The results of regression analysis indicate that management support, staff welfare organization and internal organizational climate are among the most important factors while other component did not represent any significance on knowledge management implementation.
\end{abstract}

(c) 2013 Growing Science Ltd. All rights reserved. 
tools and concept of knowledge. The other factors including management, knowledge measurement and change management were in lower levels of importance.

Akbari et al. (2012) discussed that implementation of strategic knowledge management need specific organization structure because of unique and particular characteristics of knowledge. In fact, by passing through industry age toward knowledge age, strategic knowledge management has been taken into account by organizations dramatically and by considering this new competitive edge, universities must prepare a suitable background for strategic knowledge management by encoding strategy and personalizing strategy. Akbari et al. (2012) investigated whether there was a meaningful relationship between organizational structure, in terms of recognition, focus and complexity, and strategic knowledge management, in terms of codification strategy and personalization strategy, in Azad University, Kermanshah. In this survey, organizational structure was studied as independent variables and strategic knowledge management was taken into account as dependent variables. The results of the research demonstrated that there was a meaningful relationship between organizational structure and strategic knowledge management in Azad University, Kermanshah, according to codification and personalization strategy.

Asgarian (2012) investigated relationship between knowledge management capacity and innovation performance. In this survey, knowledge management capacity incorporated knowledge application, knowledge sharing and knowledge acquisition. The study considered most important indicators including administrative innovation, product innovation, and process innovation and reported that there was not any positive relationship between knowledge acquisition and administrative innovation.

Ali et al. (2012) investigated the relationship between knowledge management practices and the organizational performance of Pakistan's telecommunication. They reported that knowledge management practices had positive and significant effect on organizational performance, which reflected that organizations that prefer knowledge management practices get beneficial outcomes than their competitors. Liao et al. (2011) studied whether knowledge management could be a mediator between organizational structure and organization environment. Zheng et al. (2010) investigated the impact of culture, organizational effectiveness, structure, strategy on knowledge management. The results demonstrated that the knowledge management was a mediator between organization culture effects on organizational effectiveness. Besides, knowledge management was a mediator between organization structure impacts and strategy effects on organizational effectiveness.

In this paper, we present an empirical study to understand the main cultural factors influencing establishment of knowledge management.

\section{The proposed model}

The proposed study of this paper considers two hypotheses as follows,

1. What are the cultural factors influencing knowledge management establishment in educational organization of Iran?

2. How could we prioritize important factors influencing knowledge management establishment in educational organization of Iran?

There are also some sub hypotheses associated with the proposed study of this paper, which are as follows,

1. There is a relationship between management support (MS) and establishment of a knowledge management system in educational organization of Iran.

2. There is a relationship between organizational affiliation (OA) and establishment of a knowledge management system in educational organization of Iran. 
3. There is a relationship between employee participation (EP) in decision-making and establishment of a knowledge management system in educational organization of Iran.

4. There is a relationship between staff welfare organization (WO) and establishment of a knowledge management system in educational organization of Iran.

5. There is a relationship between adaptation of new policies (NP) and organizational and establishment of a knowledge management system in educational organization of Iran.

6. There is a relationship between internal organizational climate (IOC) and establishment of a knowledge management system in educational organization of Iran.

The proposed study of this paper uses different educational offices in city of Tehran, Iran. There were approximately 1300 officers and managers working in this city as managers. Therefore we could use the following formula to calculate the minimum number of sample size,

$n=\frac{N \times z_{\alpha / 2}^{2} \times p \times q}{\varepsilon^{2} \times(N-1)+z_{\alpha / 2}^{2} \times p \times q}$,

where $N$ is the population size, $p=1-q$ represents the yes/no categories, $z_{\alpha / 2}$ is CDF of normal distribution and finally $\varepsilon$ is the error term. Since we have $p=0.5, z_{\alpha / 2}=1.96$ and $N=1300$, the number of sample size is calculated as $n=114$. All questions were designed in Likert scale where one represents completey disagree and five represents completely agree. The proposed study of this paper uses regression analysis to invesigate the relationship between knowledge management as dependent variable and management support (MS), organizational affiliation (OA), employee participation (EP) in decision-making, staff welfare organization (WO) and establishment, adaptation of new policies (NP) and organizational and internal organizational climate (IOC) as follows,

$$
K M=\beta_{0}+\beta_{1} M S+\beta_{2} O A+\beta_{3} E P+\beta_{4} W O+\beta_{5} N P+\beta_{6} I O C+\varepsilon,
$$

\section{The results}

\subsection{Regression analysis}

We first use regression analysis to find the relationship between knowledge manegement and different influencing items, which is as follows,

$$
\begin{aligned}
& K M=-0.433+0.186 M S+0.082 O A+0.090 E P+0.407 W O-0.008 N P+0.127 I O C+\varepsilon \text {, }
\end{aligned}
$$

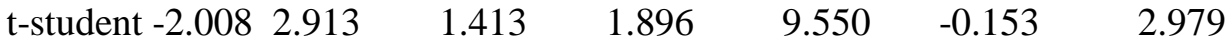

$$
\begin{aligned}
& \begin{array}{llllllll}
\text { Sig. } & 0.047 & 0.004 & 0.161 & 0.061 & 0.000 & 0.878 & 0.004
\end{array}
\end{aligned}
$$

\subsubsection{The first hypothesis: management support}

The result of Pearson correlation ratio between management support and knowledge management is equal to 0.363 , which means there is mild relationship between these two variables. The results of regression analysis also indicate that management support plays the most important effect on the success of knowledge management. Therefore, we need to look for more management cooperation when knowledge management is supposed to be applied.

\subsubsection{The Second hypothesis: organizational affiliation}

The result of Pearson correlation ratio between management support and knowledge management is equal to 0.33 , which means there is weak relationship between these two variables. The results of 
regression analysis also indicate that organizational affiliation does not play an important effect for the success of knowledge management establishment.

\subsubsection{The third hypothesis: employee participation}

The results of regression analysis also indicate that employee participation is not an important factor for the success of knowledge management establishment. The result could imply that employee participation could influence knowledge management establishment along with other factors.

\subsubsection{The fourth hypothesis: staff welfare organization}

The result of Pearson correlation ratio between staff welfare organization and knowledge management is equal to 0.289 , which means there is a positive relationship between these two variables. The results of regression analysis also indicate that staff welfare organization plays the most important effect on the success of knowledge management. Therefore, we need to look for more staff welfare organization when knowledge management is supposed to be applied.

\subsubsection{The fifth hypothesis: adaptation of new policies}

The results of regression analysis also indicate that adaptation of new policies is not an important factor for the success of knowledge management establishment. The result could imply that adaptation of new policies could only impact knowledge management establishment, indirectly through other influencing factors.

\subsubsection{The sixth hypothesis: internal organizational climate}

The result of Pearson correlation ratio between internal organizational climate and knowledge management is equal to 0.259 , which means there is mild and positive relationship between these two variables. The results of regression analysis also indicate that internal organizational climate plays the most important effect on the success of knowledge management. Therefore, we need to look for more internal organizational climate when knowledge management is supposed to be applied.

\subsection{Structural equation modeling (SEM)}

We now present details of the implementation of structural equation modeling (SEM) to confirm the findings of the regression analysis. Fig. 1 demonstrates details of the proposed model along with results of factors.

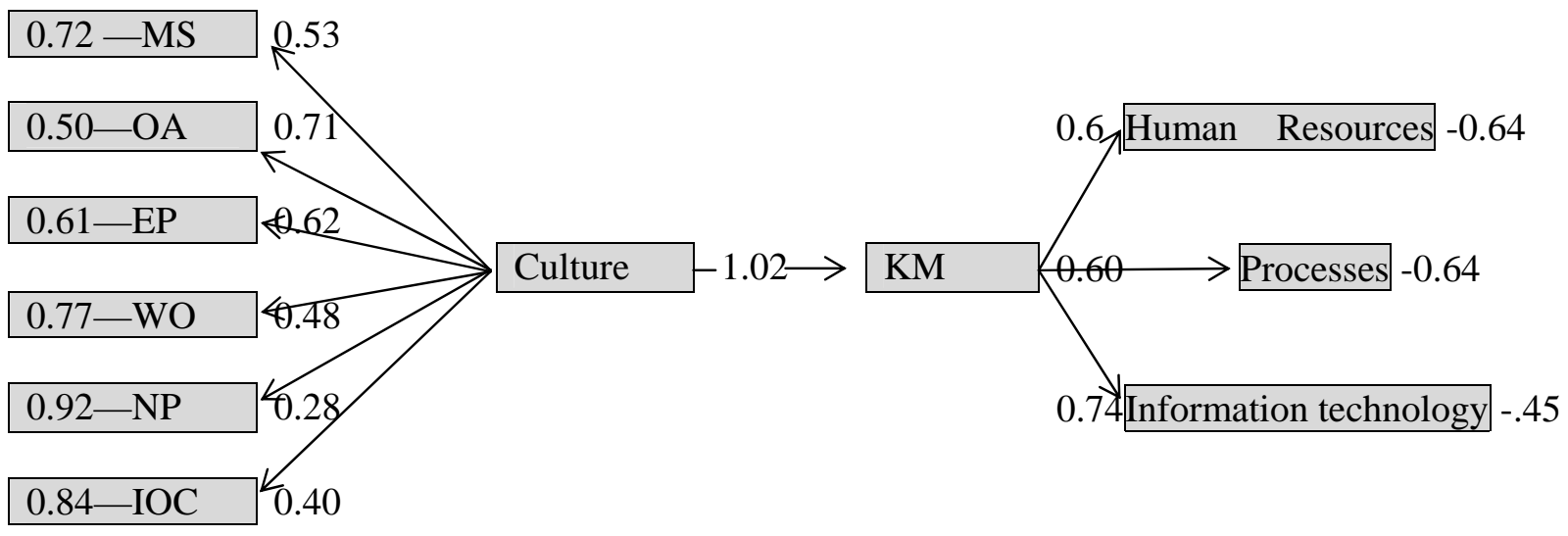

Fig. 1. The proposed framework of SEM method

According to the conceptual model, culture influences six components of management support (KS), organizational affiliation (OA), employee participation (EP) in decision-making, staff welfare 
organization (WO) and establishment, adaptation of new policies (NP) and organizational and internal organizational climate (IOC) on one sde and impacts knowledge management. In addition, knowledge management impacts human resource, processes and information technology.

In order to validate the results, we have used Kaiser-Meyer-Olkin (KMO) measure of sampling adequacy and the value of the test have been calculated as 0.73 and Chi-Square has been calculated as 906.310, which validates the results and we can confirm the results. Fig. 2 shows details of t-student values associated with each component of the study.

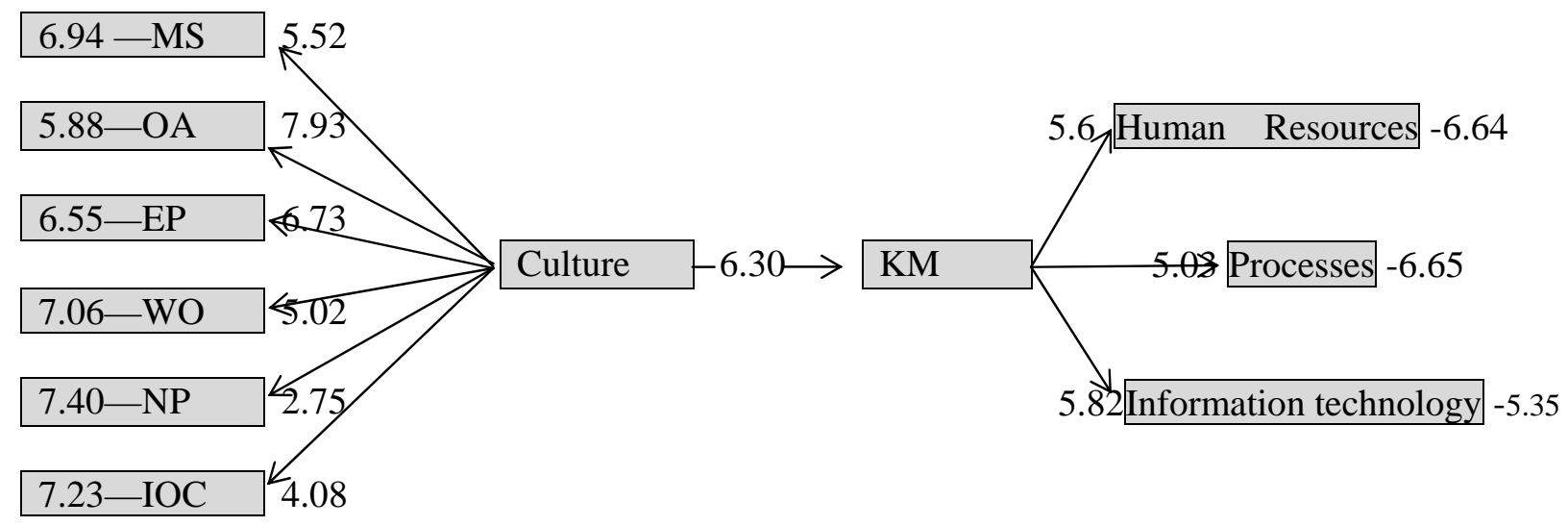

Fig. 2. The results of t-student values for SEM method

Based on the results of Fig. 2, all t-student values are greater than 1.96, which validate the results of our investigation. RMSEA is equal to 0.079 , with Chi-Square $=44.25$, which is less than 0.1 and validates the results. In summary, we can conclude that an increase of one standard deviation on staff welfare organization will reduce 0.592 in standard deviation of culture, an increase of one standard deviation on management support will reduce 0.184 in standard deviation of culture and, finally, one standard deviation on internal organizational climate will reduce 0.592 in standard deviation of culture.

\section{Conclusion}

We have presented an empirical investigation to measure the impact of six cultural based factors including management support, organizational affiliation, employee participation in decision-making, staff welfare organization and establishment, adaptation of new policies and organizational and internal organizational climate on establishment of knowledge management. The proposed study of this paper was implemented in 114 selected educational organizations in city of Tehran, Iran. A questionnaire has been designed in Likert scale and it was distributed among experts, and using regressions analysis and structural equation modeling, we have analyzed the data. The results of regression analysis have indicated that management support, staff welfare organization and internal organizational climate were among the most important factors while other component did not represent any significance on knowledge management implementation.

Acknowledgment

The authors would like to thank the annonymous referees for constructive comments on earlier version of this paper. 


\section{References}

Akbari, P., Eslampanah, M., Baharestan, O., \& Mohammadi, S. (2012). The study of relationship between organizational structure and strategic knowledge management in Islamic Azad University, Kermanshah Branch. Management Science Letters, 2(6), 1921-1930.

Ali, S.M., Qadus, A. Waseem, A., \& Zaman, K. (2012). Linking knowledge management practices and the organizational performance of Pakistan's telecommunication. Management Science Letters, 2(8), 2929-2938.

Asgari, N. (2005). The analysis of organizational factors with management of knowledge. M.A. Thesis Tehran university.

Asgarian, N. (2012). Knowledge management capacity and innovation performance. Management Science Letters, 2(8), 2739-2746.

Azad, N., \& Mehrabi Majolan, E. (2012). A study on effects of knowledge management on organizational entrepreneurship: A case study of educational system. Management Science Letters, 2(8), 2711-2716.

Liao, C., Chuang, S. H., \& To, P.L. (2011). How knowledge management mediates the relationship between environment and organizational structure. Journal of Business Research, 64, 728-736.

Zheng, W., Yang, B., \& McLean, G.N. (2010). Linking organizational culture, structure, strategy, and organizational effectiveness: Mediating role of knowledge management. Journal of Business Research, 63(7), 763-771 